\title{
When Can I Drive After Orthopaedic Surgery? A Systematic Review
}

\author{
Kevin J. DiSilvestro BA, Adam J. Santoro BS, Fotios P. Tjoumakaris MD, \\ Eric A. Levicoff MD, Kevin B. Freedman MD, MSCE
}

Received: 1 May 2016/Accepted: 25 July 2016/Published online: 4 August 2016

(C) The Association of Bone and Joint Surgeons(B) 2016

\begin{abstract}
Background Patients often ask their doctors when they can safely return to driving after orthopaedic injuries and procedures, but the data regarding this topic are diverse and sometimes conflicting. Some studies provide observer-reported outcome measures, such as brake response time or simulators, to estimate when patients can safely resume driving after surgery, and patient survey data describing when patients report a return to driving, but they do not all agree. We performed a systematic review and quality appraisal for available data regarding when patients are safe to resume driving after common orthopaedic surgeries and injuries affecting the ability to drive.
\end{abstract}

Each author certifies that he or she has no commercial associations that might pose a conflict of interest in connection with the submitted article. There was no funding or financial support for this study. All ICMJE Conflict of Interest Forms for authors and Clinical Orthopaedics and Related Research ${ }^{\circledR}$ editors and board members are on file with the publication and can be viewed on request.

This study was performed at The Rothman Institute, Philadelphia, PA, USA.

K. J. DiSilvestro

University of Maryland School of Medicine, Baltimore, MD, USA

\author{
A. J. Santoro \\ Philadelphia College of Osteopathic Medicine, Philadelphia, PA, \\ USA
}

F. P. Tjoumakaris, E. A. Levicoff, K. B. Freedman Rothman Institute, Department of Orthopaedic Surgery, Thomas Jefferson University, Philadelphia, PA, USA

K. B. Freedman $(\square)$

Rothman Institute, Department of Orthopaedic Surgery, 825 Old Lancaster Road, Suite 200, Bryn Mawr, PA 19010, USA

e-mail: kevin.freedman@ rothmaninstitute.com
Questions/purposes Based on the available evidence, we sought to determine when patients can safely return to driving after (1) lower extremity orthopaedic surgery and injuries; (2) upper extremity orthopaedic surgery and injuries; and (3) spine surgery.

Methods A search was performed using PubMed and EMBASE $^{\circledR}$, with a list of 20 common orthopaedic procedures and the words "driving" and "brake". Selection criteria included any article that evaluated driver safety or time to driving after major orthopaedic surgery or immobilization using observer-reported outcome measures or survey data. A total of 446 articles were identified from the initial search, 48 of which met inclusion criteria; abstractonly publications and non-English-language articles were not included. The evidence base includes data for driving safety on foot, ankle, spine, and leg injuries, knee and shoulder arthroscopy, hip and knee arthroplasty, carpal tunnel surgery, and extremity immobilization. Thirty-four of the articles used observer-reported outcome measures such as total brake time, brake response time, driving simulator, and standardized driving track results, whereas the remaining 14 used survey data.

Results Observer-reported outcome measures of total brake time, brake response time, and brake force postoperatively suggested patients reached presurgical norms 4 weeks after right-sided procedures such as TKA, THA, and ACL reconstruction and approximately 1 week after leftsided TKA and THA. The collected survey data suggest patients resumed driving 1 month after right-sided and leftsided TKAs. Patients who had THA reported returning to driving between 6 days and 3 months postoperatively. Observer-reported outcome measures showed that patients' driving abilities often are impaired when wearing an immobilizing cast above or below the elbow or a shoulder sling on their dominant arm. Patients reported a return to 
driving on average 2 months after rotator cuff repair procedures and approximately $1-3$ months postoperatively for total shoulder arthroplasties. Most patients with spine surgery had normal brake response times at the time of hospital discharge. Patients reported driving 6 weeks after total disc arthroplasty and anterior cervical discectomy and fusion procedures.

Conclusions The available evidence provides a best-case scenario for when patients can return to driving. It is important for observer-reported outcome measures to have normalized before a patient can consider driving, but other factors such as strength, ROM, and use of opioid analgesics need to be considered. This review can provide a guideline for when physicians can begin to consider evaluating these other factors and discussing a return to driving with patients. Survey data suggest that patients are returning to driving before observer-reported outcome measures have normalized, indicating that physicians should tell patients to wait longer before driving. Further research is needed to correlate observer-reported outcome measures with adverse events, such as motor vehicle accidents, and clinical tests that can be performed in the office.

Level of Evidence Level III, therapeutic study

\section{Introduction}

A frequently asked question in orthopaedic clinics is "when can I drive?" The National Highway Traffic Safety Administration has recommendations regarding returning to driving with certain medical conditions and procedures, but these recommendations have not been proven to reduce crash risk and are not intended for use as formal practice guidelines [62]. There currently are no standard guidelines indicating when a patient can resume driving after orthopaedic surgery. Fractures, arthroscopy, arthroplasty, and limb immobilization can affect a patient's ability to drive safely, and all may do so to different degrees. Patients desire to quickly resume driving, as the inability to drive can be disruptive, whereas physicians often wish for patients to temporarily hold off driving, allowing time for the patients to heal, and preventing them from getting in accidents because of their current condition.

Several review articles $[8,18,40,52]$ have discussed the issue of driving after orthopaedic surgery and injuries. These articles discussed observer-reported outcome measures such as brake response time, brake force, and simulators that have been used to evaluate driving ability. Procedures such as TKA have a substantial effect on brake response time, but the postoperative duration of this effect was reported to range from as brief as 10 days to as long as 8 weeks [40]. Similar discrepancies exist for other procedures such as THA, with one study [39] suggesting a return to driving at 6 weeks whereas others recommended 8 weeks $[15,18]$. To our knowledge, these controversies have not been approached using a systematic review, and the discussion of driving after orthopaedic surgery can be enhanced with inclusion of postoperative patient survey data and quality appraisal of any relevant articles.

To provide surgeons assistance in handling the issue of driving after orthopaedic procedures and injuries, we systematically reviewed the current literature to answer the following questions: (1) When can patients safely return to driving after lower extremity orthopaedic surgery and injuries? (2) When can patients safely return to driving after upper extremity orthopaedic surgery and injuries? (3) When can patients safely return to driving after spine surgery?

\section{Search Strategy and Criteria}

To answer our research questions, we identified the 20 most-common orthopaedic procedures [16], to be separated by upper extremity, lower extremity, and spine categories. Two authors (KJD, AJS) independently performed searches of PubMed and EMBASE ${ }^{\circledR}$ from inception to July 2015 for any eligible articles using the words "driving" and "brake" combined with each of the previously identified orthopaedic procedures. We searched a combination of key words including the search terms to capture all relevant articles. For example, we searched "knee arthroscopy and meniscectomy driving" and "knee arthroscopy driving", then repeated but substituting the word "brake" for "driving". Inclusion criteria were any English-language article that primarily evaluated driver safety or time to return to driving after major orthopaedic surgery and immobilization. Studies evaluating either observer-reported outcome measures of driver function and/or survey data were eligible for inclusion. Observer-reported outcome measures were defined as a measurement that could be evaluated and compared, such as brake response time or a score in a driving simulator. These measures are only one aspect of safe driving, and do not include other crucial factors such as the use of scheduled narcotics. All references from selected studies were reviewed to identify any additional articles that may have been overlooked or were not indexed in the electronic databases. Abstracts were not included in the review nor were non-English-language articles, articles that included nonorthopaedic procedures, and articles that did not specifically evaluate return to driving with either observer-reported outcome measures or survey data. Articles identified from references that discussed limb immobilization were included in our analysis. 
Qualitative assessment of included studies was performed using the Methodological Index for Nonrandomized Studies (MINORS) checklist by one author (KJD) [56]. Noncomparative studies can receive an ideal score of 16 and comparative studies can receive an ideal score of 24.

\section{Study Selection}

An initial literature search yielded 446 references. Based on title and abstract, 381 were excluded as duplicates, abstracts, published in foreign languages, or irrelevant (Fig. 1). Of the 65 remaining articles, 38 met eligibility criteria for our study. Ten additional articles were identified after reviewing references, for a total of 48 articles (Table 1). Two of these articles discussed procedures that were not on our original list, one was not indexed in either database, one did not have driving as a primary focus, and the remaining six articles discussed driving with limb immobilization. Thirty-four articles had data relevant to our study Question $1[1,4,5,9,10,12,13,15,19,22$, 23, 26-30, 34, 36, 37, 39, 41, 42, 45-50, 53, 55, 57, 60, 63, 64], eight had data relevant to Question 2 $[2,6,7,17,20,21,43,46]$, and seven had data relevant to Question 3 [3, 31, 32, 35, 54, 58, 59] (Table 1). The range of MINORS scores for comparative studies was 17 to 24 , and the range for noncomparative studies was 11 to 15 .

\section{Data Collection}

The following data from the included studies were collected and extracted by two authors (KJD, AJS) to spreadsheet software for analysis: (1) study details, including study design and level of evidence; (2) study population details, including the number of patients, the

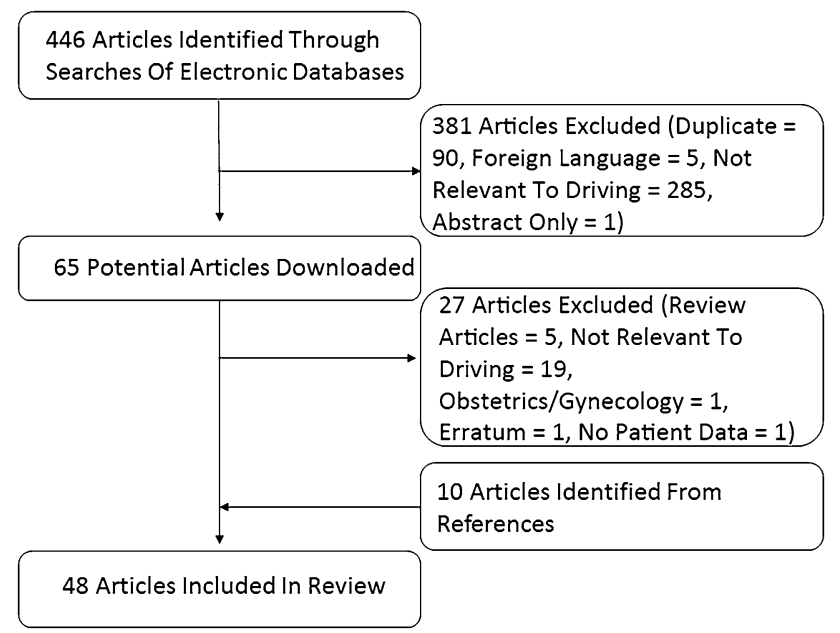

Fig. 1 The PRISMA flow diagram of our literature search is shown injury or surgical procedure performed, and laterality of the injury or procedure; (3) the method of evaluating returning to driving, including when assessments were made relative to injury or procedure, whether there was a control group, and (4) the results of the evaluation (Appendix 1).

Study Design and Populations

Brake response time was reported in 27 articles $[3,9,10,12,15,19,22,23,26,32,35-37,39,41,42,47$, $48,50,53,54,57-60,63,64]$. Brake response time is the amount of time elapsed between the appearance of a stimulus and when contact was made with a brake pedal. Total brake time was reported in six articles $[13,26,28,30,48,60]$. Total brake time is the amount of time elapsed between the appearance of a stimulus and when a brake pedal is fully depressed. Brake force was reported in four articles [30, 39, 60, 64]. Upper extremity immobilization studies used driving abilities score, simulators, and standardized tracks [6, 7, 20, 21]. The driving score reflected specific activities of driving such as steering and signaling [6]. The driving simulators evaluated participants' ability to avoid hazards and collisions. Two studies included data regarding a stepping test and a standing test $[22,47]$. The stepping test counts how many times a patient can plant his or her foot on alternating sides of an obstacle in 10 seconds. The standing test counts how many times a patient can transition between a seated position and a standing position in 10 seconds. One article included a different type of step test that involved maintaining balance on the involved limb while using the contralateral limb to step on and off a $15-\mathrm{cm}$ step as quickly as possible [9]. Survey data of when patients reported return to driving were published in 14 articles $[1,2,4,5,17,27,29,31,34,43,45,46,49,55]$.

Table 1. Description of included articles

\begin{tabular}{ll}
\hline Number of articles & Description \\
\hline 3 & Ankle injuries \\
2 & Foot injuries \\
1 & Articular, femur, and tibial shaft fractures \\
5 & Knee arthroscopy \\
9 & Knee arthroplasty \\
9 & THA \\
1 & Hip, shoulder, and knee arthroplasty \\
4 & Lower extremity immobilization \\
2 & Shoulder arthroscopy \\
1 & Carpal tunnel surgery \\
4 & Upper extremity immobilization \\
7 & Spine surgery \\
\hline
\end{tabular}




\section{Results}

Safely Driving after Lower Extremity Orthopaedic Injuries and Procedures

\section{Observer-reported Outcome Measures}

Patients with a right ankle fracture treated operatively had total brake times not significantly different from those of controls at 9 weeks postoperatively [13] and brake response times back to normal 1 week after cast removal [64] (Table 2). Patients with a right first metatarsal osteotomy had significantly improved brake response times at 6 weeks [26]. Patients with right articular fractures (plateau, pilon, calcaneus, and acetabulum) and those with right tibial shaft or femur fractures had significantly improved brake response times 6 weeks after initiation of weightbearing therapy [12]. Patients with ACL reconstruction had normal brake response times 4 to 6 weeks after surgery on the right $[19,47]$ and 2 weeks after surgery on the left [47]. There also are data showing that clinical tests, such as the stepping and standing tests, were strongly correlated with observerreported outcome measures of driving ability after ACL reconstruction [47]. Patients with smaller arthroscopic procedures such as partial meniscectomies, chondroplasties, and diagnostic arthroscopies, had elevated brake response times for at least 1 week after surgery [22]. A similar correlation was found in these patients between stepping and standing tests and brake response time [22]. Patients with a right TKA had normal brake response times and total brake times 2 to 8 weeks postoperatively [9, 28, 36, 37, 42, 50, 57] and normal brake response times 0 to 3 weeks after a left TKA [36, 37, 41, 50, 57]. Data showed that a step test was the best predictor of safety when correlated with total brake time after TKA [28]. Patients with THAs had normal brake response times, total brake times, and brake forces 2 to 8 weeks after right-sided procedures $[15,23,30,39,53]$ and 1 to 8 weeks after left-sided procedures [15, 30, 39]. Driving measures such as brake response time, total brake time, and brake force were significantly impaired when a driver wore a right lower-extremity hard cast, aerated orthosis, controlled ankle-motion cast, short leg cast, above- or belowknee plaster cast, or ROM-restricting brace [10, 48, 60, 63].

\section{Survey Measures}

Patients with operative Achilles tendon repair reported a return to driving at an average of 49 days, which correlated with full weightbearing status [29] (Table 3). Patients with a 5th metatarsal avulsion fracture reported a return to driving at 6 weeks when treated with a walking boot and 12 weeks after injury when treated with a short leg cast [55].
After arthroscopic procedures such as meniscectomies, chondroplasties, and diagnostic arthroscopies, patients reported returning to driving between 1 day and 3 weeks after surgery $[4,34]$. After right TKA, $48 \%$ of patients were driving within 1 month compared with $57 \%$ who had a left TKA [27], whereas a survey with no distinction of laterality showed $25 \%$ of patients driving within 1 month and an additional $71 \%$ driving 1 to 3 months postoperatively [46]. Patients who had THAs reported driving as early as 6 days and as late as 3 months postoperatively $[1,5,45,46,49]$.

Safely Driving after Upper Extremity Orthopaedic Injuries and Procedures

\section{Observer-reported Outcome Measures}

Driving simulators and standardized tracks showed that driving ability is impaired when patients wear a right or left scaphoid and Bennett's cast, above- or below-elbow immobilization, or a shoulder sling on the dominant arm $[6,7,20,21]$ (Table 4). No articles that evaluated observerreported outcome measures after upper extremity surgery matched our search criteria.

\section{Survey Measures}

Patients reported returning to driving after rotator cuff repair between the same day to 4 months postoperatively [17] (Table 5). After right or left arthroscopic subacromial decompression, patients reported returning to driving 1 month, on average, after surgery [43]. Thirty-nine percent of patients with right or left total shoulder arthroplasty resumed driving within 1 month and another 55\% resumed driving within 1 to 3 months [46]. Patients with open carpal tunnel surgery reported returning to driving 9 days, on average, after surgery [2].

\section{Safely Driving after Spine Surgery}

\section{Observer-reported Outcome Measures}

Patients with lumbar discectomy for radiculopathies [58], cervical and lumbar decompression and/or fusion [35, 54], and standard posterior sequestrectomy or subtotal discectomy [59] did not have an elevated brake response time at the time of discharge from the hospital (Table 6). However, patients with anterior cervical fusion had elevated brake response time compared with healthy control subjects [32]. Patients with radiculopathy and selective nerve 


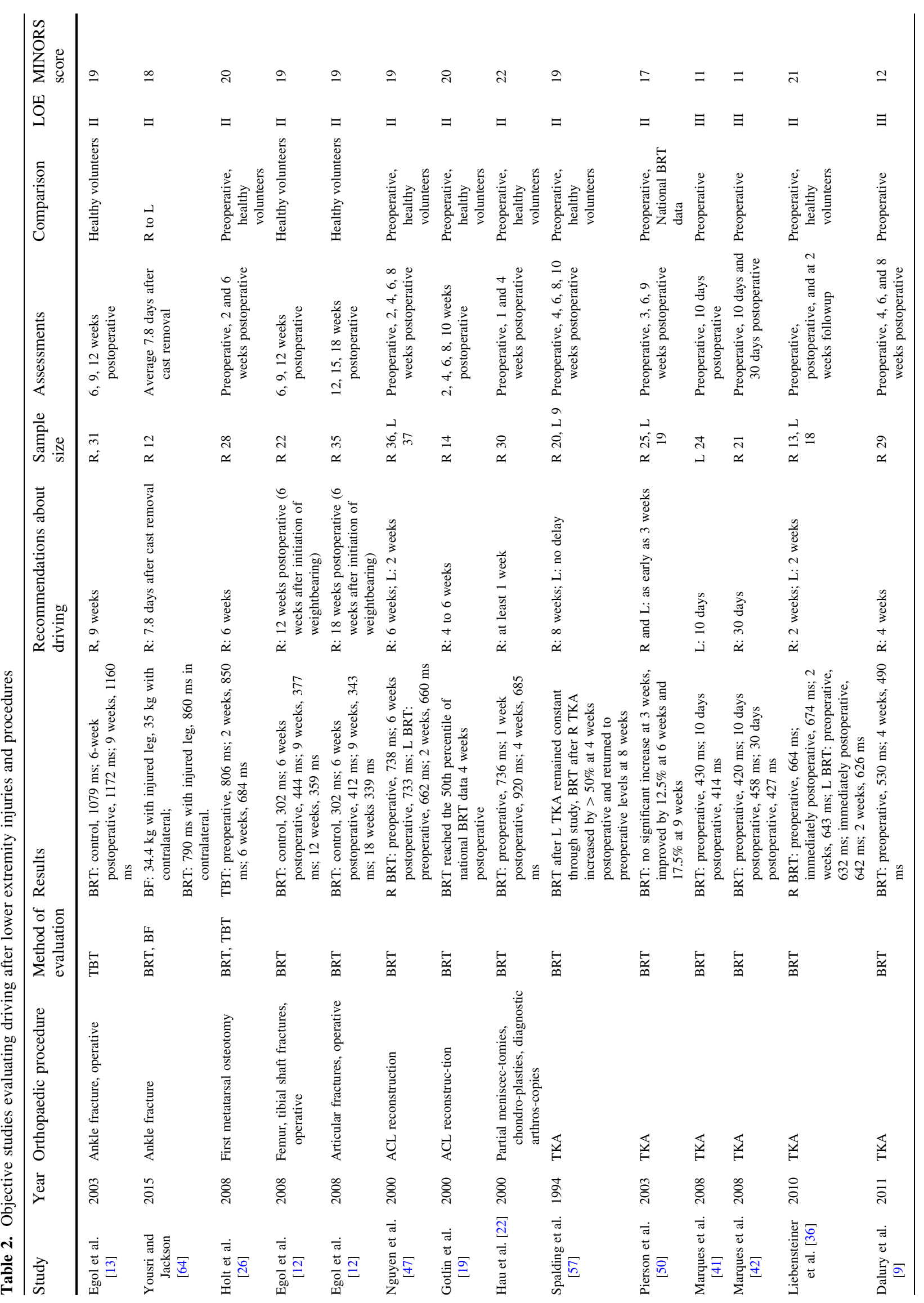




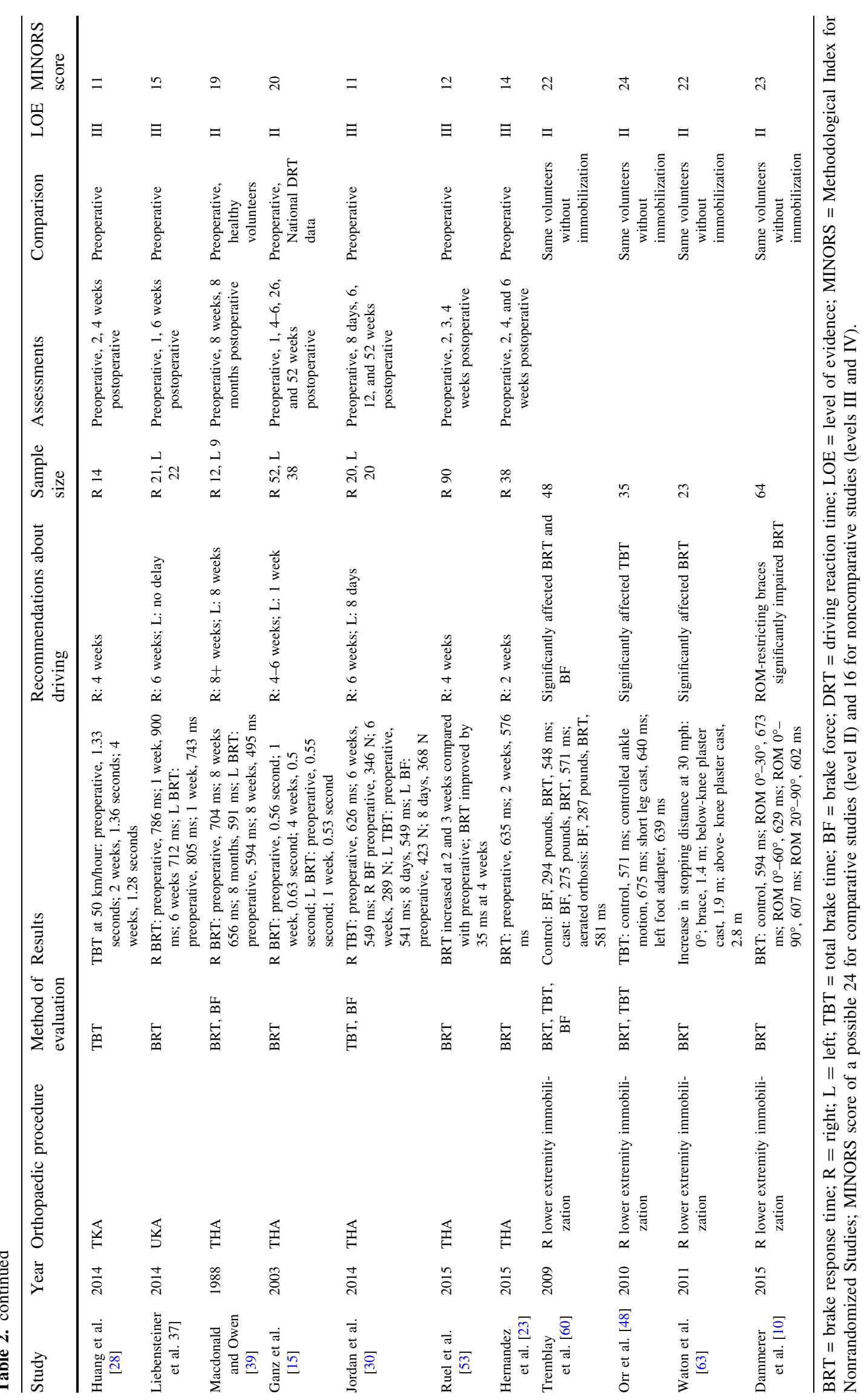




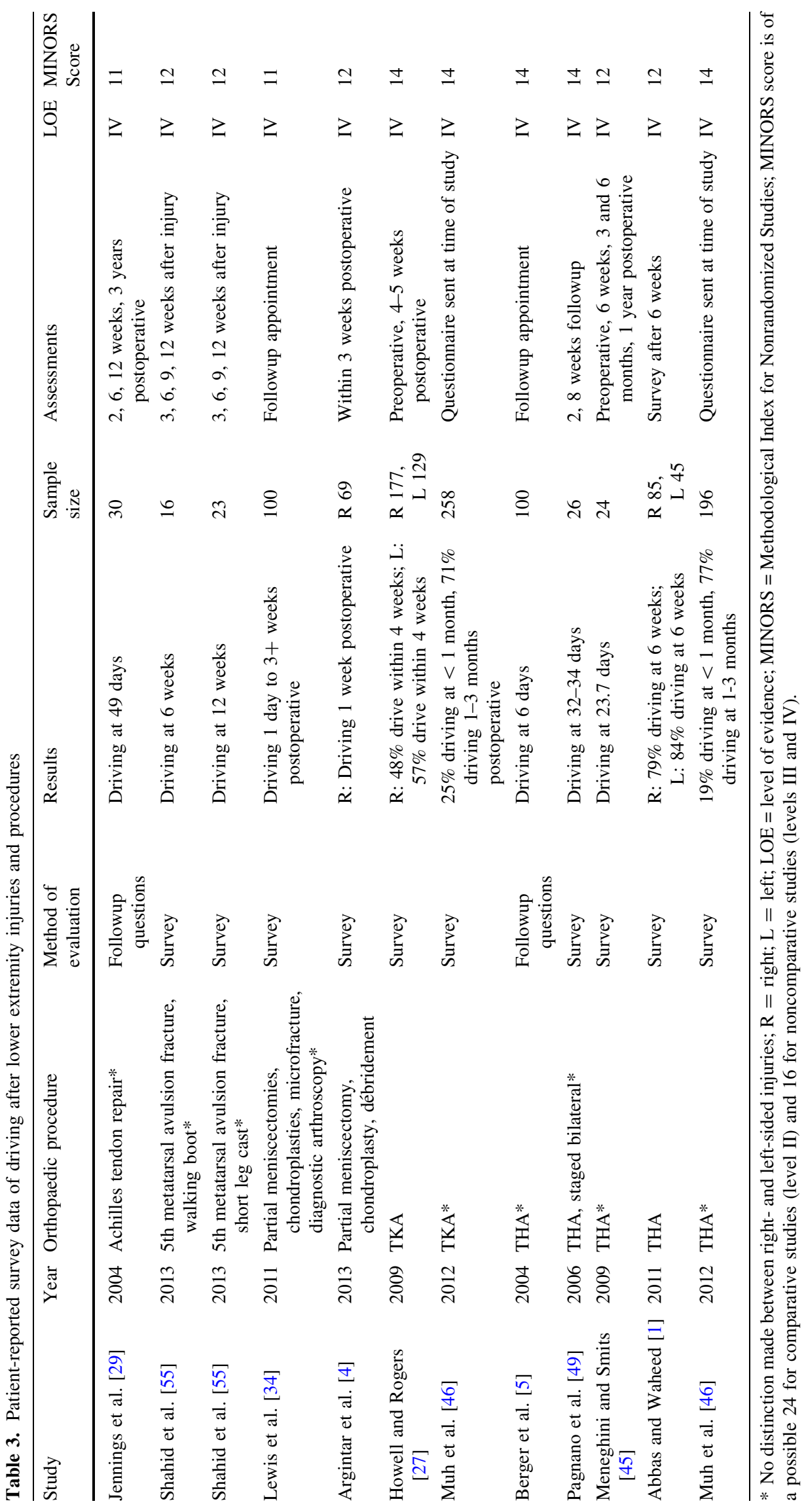




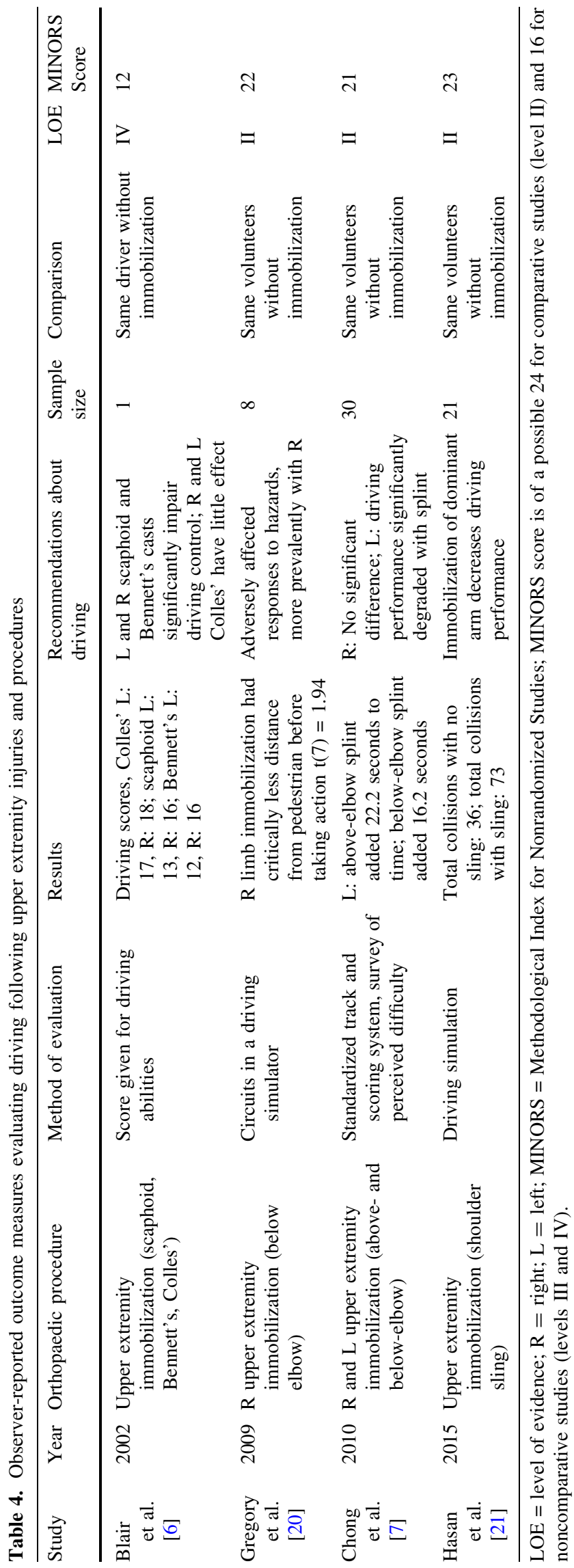

root blocks had significantly elevated brake response times at 6 weeks with right nerve blocks but returned to baseline at 2 weeks after a left block [3].

\section{Survey Measures}

Patients with cervical disc arthroplasty or anterior cervical discectomy and fusion reported a return to driving, on average, 6 weeks after surgery [31] (Table 7).

\section{Discussion}

Patients frequently ask their orthopaedic surgeons when they can return to driving after various injuries and procedures. There are no standard guidelines that surgeons can use to advise patients. Orthopaedic injuries and operations can have a profound effect on the ability to drive. Pain and limitation in motion or function of upper and lower extremities can substantially affect driving safety. Several reviews on this topic have been published [8, 18, 40, 52], however in this study, we expanded on previously published reviews by performing a search in a systematic format, evaluating the quality of the studies, and including data from patient surveys. In addition, prior reviews focused primarily on one procedure or types of procedure, without compiling these data in a systematic format or recommendations. We attempted to answer the following research questions in this review: (1) When can patients safely return to driving after lower extremity orthopaedic surgery and injuries? (2) When can patients safely return to driving after upper extremity orthopaedic surgery and injuries? (3) When can patients safely return to driving after spine surgery?

As with many systematic reviews, our study was limited by the quality and quantity of the existing literature on the topic. The most frequently referenced observer-reported outcome measure for driving is the brake response time $[3,9,10,12,15,19,22,23,26,32,35-37,39,41,42,47$, $48,50,53,54,57-60,63,64]$. Evaluations such as the brake response time are not perfect estimators of driving ability as there are many more obstacles and distractions on a road compared with a simulation. More importantly, these simulators represent best-case scenarios for when patients can safely return to driving. A patient should not return to driving before his or her brake response time has normalized, but there are other factors that also affect driving ability. A patient may have a normal brake response time 10 days after left TKA [41], but clearly is not ready for driving if he or she still is using a walker or still is taking narcotic analgesics. The studies reporting observerreported outcome measures also had relatively small 
Table 5. Patient-reported survey data of driving after upper extremity injuries and procedures

\begin{tabular}{|c|c|c|c|c|c|c|c|c|}
\hline Study & Year & $\begin{array}{l}\text { Orthopaedic } \\
\text { procedure }\end{array}$ & $\begin{array}{l}\text { Method of } \\
\text { evaluation }\end{array}$ & Results & $\begin{array}{l}\text { Sample } \\
\text { size }\end{array}$ & Assessments & LOE & $\begin{array}{l}\text { MINORS } \\
\text { score }\end{array}$ \\
\hline $\begin{array}{l}\text { McClelland et al. } \\
\text { [43] }\end{array}$ & 2005 & $\begin{array}{l}\text { Subacromial } \\
\text { decompression* }\end{array}$ & Survey & $\begin{array}{l}\text { Driving } 28.9 \text { days } \\
\text { postoperative }\end{array}$ & 68 & $\begin{array}{c}\text { Preoperative, } 3 \text { weeks, } 3 \\
\text { months postoperative }\end{array}$ & IV & 14 \\
\hline Muh et al. [46] & 2012 & $\begin{array}{l}\text { Total shoulder } \\
\text { arthroplasty* }\end{array}$ & Survey & $\begin{array}{l}39 \% \text { driving }<1 \text { month, } \\
55 \% \text { driving } 1-3 \\
\text { months postoperative }\end{array}$ & 31 & $\begin{array}{l}\text { Questionnaire sent at } \\
\text { time of study }\end{array}$ & IV & 14 \\
\hline $\begin{array}{l}\text { Gholson et al. } \\
\text { [17] }\end{array}$ & 2015 & Rotator cuff repair* & Survey & $\begin{array}{l}\text { Driving same day to } 4 \\
\text { months postoperative } \\
\text { (median } 2 \text { months) }\end{array}$ & 54 & 4 months postoperative & IV & 13 \\
\hline $\begin{array}{l}\text { Acharya and } \\
\text { Auchincloss } \\
\text { [2] }\end{array}$ & 2005 & $\begin{array}{l}\text { Open carpal } \\
\text { tunnel surgery }\end{array}$ & Survey & $\begin{array}{l}\mathrm{R} \text { and } \mathrm{L} \text { : driving at } 9 \\
\text { days }\end{array}$ & 75 & $\begin{array}{l}\text { Preoperative and } 3 \\
\text { months postoperative } \\
\text { survey }\end{array}$ & IV & 12 \\
\hline
\end{tabular}

* No distinction made between right (R)- and left (L)-sided injuries; LOE = level of evidence; MINORS = Methodological Index for Nonrandomized Studies; MINORS score is of a possible 24 for comparative studies (level II) and 16 for noncomparative studies (levels III and IV).

sample sizes, which decreases their power to pick up on subtle differences that could have important clinical consequences. These limitations would underestimate the time it takes to be ready to drive again. Additionally, the studies assessed driver readiness based on observer-reported outcome measures or patient-reported timelines to return, but do not correlate these tests with real-world adverse events, such as motor vehicle accidents or driving infractions. The application of these data also is limited by practical reasons. It can be expensive and time consuming to construct a driving simulator or machine in every orthopaedic office to measure brake response time. Other limitations included variability in reporting, as not all studies specified laterality, which can affect driving particularly for lower extremity injuries and surgery. Studies used different measures of driver safety, and several used healthy volunteers. Physicians should exercise some caution using patient-survey data regarding return to driving. Reporting return to driving does not necessarily indicate that it is safe to do so. However, given the lack of definitive data on driving safety, sharing with patients when other people with a similar condition felt safe to resume driving can be useful information as long as the survey-reported return does not occur before the observer-reported outcome measures normalize. Many variables outside observer-reported outcome measures affect safe driving. Comorbidities such as sleep apnea [14], kidney disease, stroke [38], heart disease, arthritis in females, and the use of NSAIDs, angiotensin-converting enzyme inhibitors, and benzodiazepines [44], all are associated with substantially increased risk of motor vehicle crashes and difficulty driving; conditions such as obesity [65] are associated with increased risk of fatality in a motor vehicle crash. The use of a cellular telephone quadruples the risk of collision [51]. These variables were not evaluated in published studies regarding driving safety after orthopaedic procedures, which is an additional limitation to our study.

The brake response time, total brake time, brake force, and patient-reported data were used to evaluate return to driving after lower extremity injury and orthopaedic procedures. Observer-reported outcome measures indicate that patients return to preoperative levels approximately 1 month after right ACL reconstruction, TKA, and THA. Patients with left ACL reconstruction, THA, and TKA, and those with right-knee meniscectomies, chondroplasties, and diagnostic arthroplasties reached preoperative observer-reported outcome measures 1 week after surgery. Although a patient may reach preoperative levels of observer-reported outcome measures or ones comparable to levels of healthy volunteers, it does not mean that the patient is absolutely safe to drive, as all of the other factors that affect driving safety need to be considered. Evaluation of braking function after foot, ankle, and lower extremity fractures suggested that patients return to preoperative or control ranges 6 weeks after right first metatarsal osteotomy, 9 weeks after right ankle fracture treated operatively, and 18 weeks after operative treatment of right plateau, pilon, calcaneous, and acetabulum articular fractures. It is not safe for patients with most forms of right lower extremity immobilization to drive. Clinical tests such as the stepping and standing tests correlated with measurements of brake function after TKA, ACL reconstruction, and other arthroscopic knee procedures [9, 22, 47]. Using clinical tests to evaluate driving ability is a simple and cost-effective way to help physicians provide patients with driving advice. Further research is needed to validate these tests for a broader spectrum of surgeries.

Upper extremity procedures and immobilizations were evaluated with simulators and patient-reported return to driving. Tests of braking function are not applicable with 


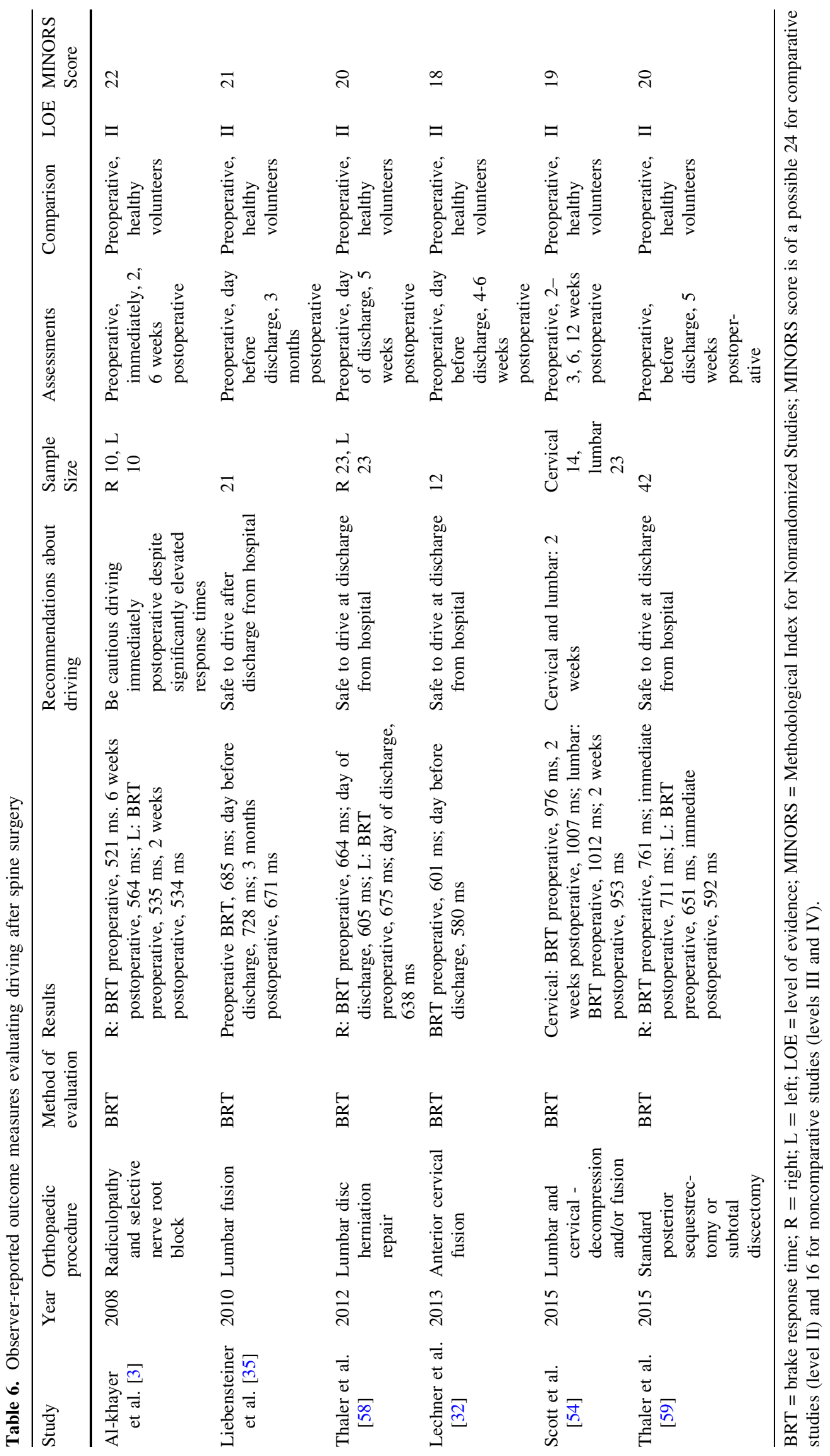




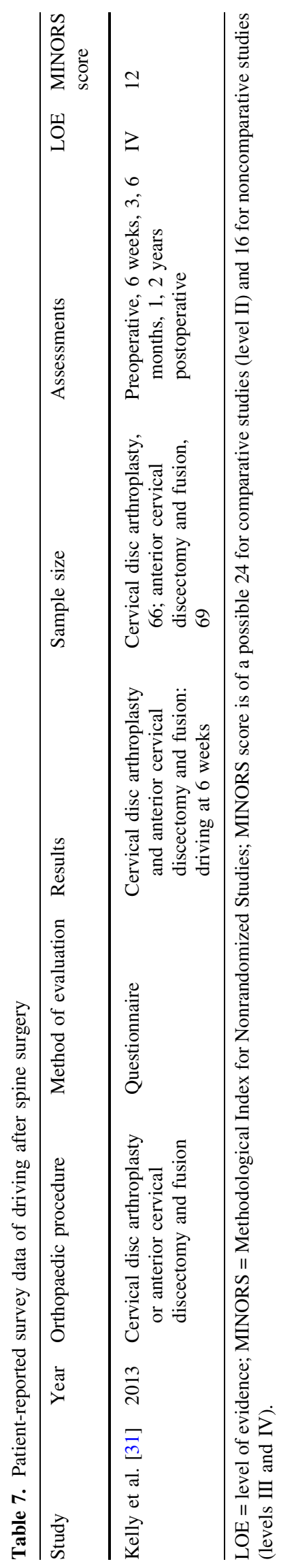

upper extremity surgeries. Healthy patients driving on courses indicated that it is unsafe for patients with most forms of upper extremity immobilization to drive $[6,7,20,21]$. A driving simulator that includes avoiding obstacles could be a better method of evaluating driving ability than an isolated evaluation of braking function, as there is more to driving and avoiding accidents than accounting for the time it takes to press the brake pedal. Additional research is needed to evaluate observer-reported outcome measures after upper extremity surgery and to identify the best method of evaluating driving readiness for these patients, potentially with a clinical test similar to the stepping and standing test used for lower extremity evaluations.

The brake response time and patient-reported return to driving were used to evaluate driving readiness after spine surgery and injuries. Observer-reported outcome measures indicate that patients with spinal procedures, such as lumbar or cervical fusion [32, 35], posterior sequestrectomy, subtotal discectomy [59], and radiculopathy and selective nerve root blocks [3] often have comparable values to those of their preoperative assessment at the time of discharge. Although the observer-reported outcome measures rapidly normalize after these procedures, physicians again are encouraged to consider all of the variables affecting safety when discussing returning to driving with patients. As described above, there also are practical limitations to using brake response time as a method of evaluating driving ability, and identifying clinical tests to evaluate readiness is an area for further studies.

Advances in evaluating patient safety in driving can be achieved through more widespread use of driving simulators and referral for official driving evaluation. Driving simulators are being used with increasing frequency in other medical fields, including evaluating patients who have had a stroke [25]. Lee et al. [33] found a sensitivity of $91.4 \%$ for driving simulators when evaluating elderly drivers with an accident history. This is an advantage over brake response time which is an intuitively highly specific test, as the inability to brake in an emergency will likely result in a crash, but potentially not as sensitive to the effect of some of the other comorbidities described above. We were unable to identify any data regarding sensitivity of the brake response time, which is another area for future research. Potentially these simulators could be used with greater frequency in the field of orthopaedics. As there can be medicolegal implications in advising patients about the safety of driving and limited-quality evidence, referring to an official driving evaluation by someone formally trained in making these assessments is an option. Official driving evaluations have been used to evaluate patients with Alzheimer's disease [24]. This option can be considered when 
multiple factors that affect safe driving are present in a patient.

\section{Other Guidelines}

Several administrative bodies also provide advice regarding safe driving. The use of opioid analgesics has been associated with an increased odds of unsafe driving [11], and the FDA advises all patients taking opioids not to drive or operate heavy machinery owing to drowsiness associated with these medications [61]. To safely drive, patients must have sufficient ROM in their neck, hands, shoulders, elbows, and ankles, and sufficient strength in these joints. The National Highway Traffic Safety Administration recommends that drivers have at least $4 / 5$ strength in both upper extremities and right lower extremity to drive safely, with 4/5 strength defined as movement against gravity and some resistance [62].

Research regarding driving after orthopaedic surgery provides limited evidence about the best-case scenario for when patients ask about a return to driving. The observerreported outcome measures used to evaluate driving readiness in these studies do not account for many important factors such as the use of opioid analgesics. A patient cannot return to driving before his or her brake response time has normalized, but this may not be the ratelimiting step on the path to recovery. This systematic review can be used as a guideline for when physicians can begin to consider evaluating if patients are ready to drive, along with an assessment of their strength, ROM, and medications (Table 8). Survey data show that patients often began driving before observer-reported outcome measures such as brake response time had normalized, which suggests that physicians should tell patients to wait longer before driving. Further research is needed to evaluate driving readiness after upper extremity surgery and to identify more clinical tests such as the stepping test and standing test that can be used to easily evaluate patients in the office setting. This can be done by identifying which observer-reported outcome measures correlate with adverse events such as motor vehicle accidents, then identifying a clinical test that is correlated with those observer-reported outcome measures. Returning to driving will not follow the same timeline for every patient, and ultimately patients must feel safe and ready to accept the risks of driving.

Table 8. Summary of timelines for observer-reported outcome measures to return to normal

\begin{tabular}{|c|c|c|}
\hline Procedure & Timeline & $\begin{array}{l}\text { Range of level of } \\
\text { evidence }\end{array}$ \\
\hline Right ankle fracture treated operatively & $\begin{array}{l}9 \text { weeks postoperatively, or } 1-2 \text { weeks after cast } \\
\text { removal }\end{array}$ & II \\
\hline Right first metatarsal osteotomy & 6 weeks postoperatively & II \\
\hline Right femur and tibial shaft fractures treated operatively & $\begin{array}{l}12 \text { weeks postoperatively, } 6 \text { weeks after initiation of } \\
\text { weightbearing }\end{array}$ & II \\
\hline $\begin{array}{l}\text { Right plateau, pilon, calcaneous, and acetabulum } \\
\text { articular fractures treated operatively }\end{array}$ & 18 weeks postoperatively, 6 weeks after weightbearing & II \\
\hline Right ACL reconstruction & 4-6 weeks postoperatively & II \\
\hline Left ACL reconstruction & 2 weeks postoperatively & II \\
\hline $\begin{array}{l}\text { Right partial meniscectomies, chondroplasties, and } \\
\text { diagnostic arthroscopies }\end{array}$ & 1 week postoperatively & II \\
\hline Right TKA & Most commonly 4 weeks, range of $2-8$ weeks & II-III \\
\hline Left TKA & $0-3$ weeks postoperatively & II-III \\
\hline Right THA & Most commonly 4 weeks, range of $2-8$ weeks & II-III \\
\hline Left THA & 1 week postoperatively & II-III \\
\hline Radiculopathy and selective nerve root block & On hospital discharge & II \\
\hline Lumbar and cervical fusion & On hospital discharge to 2 weeks & II \\
\hline Standard posterior sequestrectomy/subtotal discectomy & On hospital discharge & II \\
\hline Upper extremity immobilization & $\begin{array}{l}\text { Not safe to drive with right or left scaphoid or Bennett's } \\
\text { cast, or a shoulder sling on a patient's dominant arm. } \\
\text { Above- and below-elbow splints can degrade driving } \\
\text { performance. }\end{array}$ & II-IV \\
\hline Lower extremity immobilization & $\begin{array}{l}\text { Not safe to drive with a right hard cast, aerated orthosis, } \\
\text { controlled ankle motion cast, short leg cast, below- } \\
\text { and above-knee plaster cast, and ROM-restricting } \\
\text { brace. }\end{array}$ & II \\
\hline
\end{tabular}




\section{Appendix 1}

Data collection form

1. Title

2. Author

3. Year

4. Journal

5. Body part

6. Orthopaedic procedure/injury

7. Method used to evaluate driving status/ability

8. Laterality

9. Results

10. Recommendation about driving

11. Sample size

12. Time at which assessments are performed

13. Comparison group

14. Level of evidence

15. MINORS score

MINORS $=$ Methodological Index for Nonrandomized Studies

\section{References}

1. Abbas G, Waheed A. Resumption of car driving after total hip replacement. J Orthop Surg (Hong Kong). 2011;19:54-56.

2. Acharya AD, Auchincloss JM. Return to functional hand use and work following open carpal tunnel surgery. J Hand Surg Br. 2005;30:607-610.

3. Al-khayer A, Schueler A, Kruszewski G, Armstrong G, Grevitt MP. Driver reaction time before and after treatment for lumbar radiculopathy. Spine (Phila Pa 1976). 2008;33:1696-1700.

4. Argintar E, Williams A, Kaplan J, Hall MP, Sanders T, Yalamanchili R, Hatch GF. Recommendations for driving after right knee arthroscopy. Orthopedics. 2013;36:659-665.

5. Berger RA, Jacobs JJ, Meneghini RM, Della Valle C, Paprosky W, Rosenberg AG. Rapid rehabilitation and recovery with minimally invasive total hip arthroplasty. Clin Orthop Relat Res. 2004;429:239-247.

6. Blair S, Chaudhri O, Gregori A. Doctor, can I drive with this plaster? An evidence based response. Injury. 2002;33:55-56.

7. Chong PY, Koehler EA, Shyr Y, Watson JT, Weikert DR, Rowland JH, Lee DH. Driving with an arm immobilized in a splint: a randomized higher-order crossover trial. J Bone Joint Surg Am. 2010;92:2263-2269.

8. Cooper JM. Clinical decision making: doctor, when can I drive? Am J Orthop (Belle Mead NJ). 2007;36:78-80.

9. Dalury DF, Tucker KK, Kelley TC. When can I drive?: brake response times after contemporary total knee arthroplasty. Clin Orthop Relat Res. 2011;469:82-86.

10. Dammerer D, Giesinger JM, Biedermann R, Haid C, Krismer M, Liebensteiner M. Effect of knee brace type on braking response time during automobile driving. Arthroscopy. 2015;31:404-409.

11. Dubois S, Bédard M, Weaver B. The association between opioid analgesics and unsafe driving actions preceding fatal crashes. Accid Anal Prev. 2010;42:30-37.

12. Egol KA, Sheikhazadeh A, Koval KJ. Braking function after complex lower extremity trauma. J Trauma. 2008;65:1435-1438.
13. Egol KA, Sheikhazadeh A, Mogatederi S, Barnett A, Koval KJ. Lower-extremity function for driving an automobile after operative treatment of ankle fracture. J Bone Joint Surg Am. 2003;85:1185-1189.

14. Ellen RL, Marshall SC, Palayew M, Molnar FJ, Wilson KG, Man-Son-Hing M. Systematic review of motor vehicle crash risk in persons with sleep apnea. J Clin Sleep Med. 2006;2:193-200.

15. Ganz SB, Levin AZ, Peterson MG, Ranawat CS. Improvement in driving reaction time after total hip arthroplasty. Clin Orthop Relat Res. 2003:413:192-200.

16. Garrett WE Jr, Swiontkowski MF, Weinstein JN, Callaghan J, Rosier RN, Berry DJ, Harrast J, Derosa GP. American Board of Orthopaedic Surgery Practice of the Orthopaedic Surgeon: Part II. Certification examination case mix. J Bone Joint Surg Am. 2006;88:660-667.

17. Gholson JJ, Lin A, McGlaston T, DeAngelis J, Ramappa A. Return to driving after arthroscopic rotator cuff repair: patientreported safety and maneuverability. J Surg Orthop Adv. 2015;24:125-129.

18. Goodwin D, Baecher N, Pitta M, Letzelter J, Marcel J, Argintar E. Driving after orthopedic surgery. Orthopedics. 2013;36:469474.

19. Gotlin RS, Sherman AL, Sierra N, Kelly M, Scott WN. Measurement of brake response time after right anterior cruciate ligament reconstruction. Arthroscopy. 2000;16:151-155.

20. Gregory JJ, Stephens AN, Steele NA, Groeger JA. Effects of upper-limb immobilisation on driving safety. Injury. 2009;40:253-256.

21. Hasan S, Chay E, Atanda A, McGee AW, Jazrawi LM, Zuckerman JD. The effect of shoulder immobilization on driving performance. J Shoulder Elbow Surg. 2015;24:273-279.

22. Hau R, Csongvay S, Bartlett J. Driving reaction time after right knee arthroscopy. Knee Surg Sports Traumatol Arthrosc. 2000;8:89-92.

23. Hernandez VH, Ong A, Orozco F, Madden AM, Post Z. When is it safe for patients to drive after right total hip arthroplasty? $J$ Arthroplasty. 2015;30:627-630.

24. Hird MA, Egeto P, Fischer CE, Naglie G, Schweizer TA. A systematic review and meta-analysis of on-road simulator and cognitive driving assessment in Alzheimer's disease and mild cognitive impairment. J Alzheimers Dis. 2016 May 11. [Epub ahead of print]

25. Hird MA, Vetivelu A, Saposnik G, Schweizer TA. Cognitive, onroad, and simulator-based driving assessment after stroke. $J$ Stroke Cerebrovasc Dis. 2014;23:2654-2670.

26. Holt G, Kay M, McGrory R, Kumar CS. Emergency brake response time after first metatarsal osteotomy. J Bone Joint Surg Am. 2008;90:1660-1664.

27. Howell SM, Rogers SL. Method for quantifying patient expectations and early recovery after total knee arthroplasty. Orthopedics. 2009;32:884.

28. Huang HT, Liang JM, Hung WT, Chen YY, Guo LY, Wu WL. Timeframe for return to driving for patients with minimally invasive knee arthroplasty is associated with knee performance on functional tests. BMC Musculoskelet Disord. 2014;15:198.

29. Jennings AG, Sefton GK, Newman RJ. Repair of acute rupture of the Achilles tendon: a new technique using polyester tape without external splintage. Ann R Coll Surg Engl. 2004;86:445-448.

30. Jordan M, Hofmann UK, Grünwald J, Meyer M, Sachsenmaier S, Wülker N, Kluba T, Ipach I. Influence of left- and right-side total hip arthroplasty on the ability to perform an emergency stop while driving a car. Arch Phys Med Rehabil. 2014;95:1702-1709.

31. Kelly MP, Mitchell MD, Hacker RJ, Riew KD, Sasso RC. Singlelevel degenerative cervical disc disease and driving disability: results from a prospective, randomized trial. Global Spine J. $2013 ; 3: 237-242$. 
32. Lechner R, Thaler M, Krismer M, Haid C, Obernauer J, Obwegeser A. Driving reaction time before and after anterior cervical fusion for disc herniation: a preliminary study. Eur Spine J. 2013;22:1517-1521.

33. Lee HC, Lee AH, Cameron D, Li-Tsang C. Using a driving simulator to identify older drivers at inflated risk of motor vehicle crashes. J Safety Res. 2003;34:453-459.

34. Lewis C, Mauffrey C, Hull P, Brooks S. Knee arthroscopy and driving. Results of a prospective questionnaire survey and review of the literature. Acta Orthop Belg. 2011;77:336-338.

35. Liebensteiner MC, Birkfellner F, Thaler M, Haid C, Bach C, Krismer M. Driving reaction time before and after primary fusion of the lumbar spine. Spine (Phila Pa 1976). 2010;35:330-335.

36. Liebensteiner MC, Kern M, Haid C, Kobel C, Niederseer D, Krismer M. Brake response time before and after total knee arthroplasty: a prospective cohort study. BMC Musculoskelet Disord. 2010;11:267.

37. Liebensteiner MC, Rochau H, Renz P, Smekal V, Rosenberger R, Birkfellner F, Haid C, Krismer M. Brake response time returns to the pre-surgical level 6 weeks after unicompartmental knee arthroplasty. Knee Surg Sports Traumatol Arthrosc. 2014;22:1926-1931.

38. Lyman JM, McGwin G, Sims RV. Factors related to driving difficulty and habits in older drivers. Accid Anal Prev. 2001;33:413-421.

39. MacDonald W, Owen JW. The effect of total hip replacement on driving reactions. J Bone Joint Surg Br. 1988;70:202-205.

40. Marecek GS, Schafer MF. Driving after orthopaedic surgery. $J$ Am Acad Orthop Surg. 2013;21:696-706.

41. Marques CJ, Barreiros J, Cabri J, Carita AI, Friesecke C, Loehr JF. Does the brake response time of the right leg change after left total knee arthroplasty? A prospective study. Knee. 2008;15:295298.

42. Marques CJ, Cabri J, Barreiros J, Carita AI, Friesecke C, Loehr JF. The effects of task complexity on brake response time before and after primary right total knee arthroplasty. Arch Phys Med Rehabil. 2008;89:851-855.

43. McClelland D, Paxinos A, Dodenhoff RM. Rate of return to work and driving following arthroscopic subacromial decompression. ANZ J Surg. 2005;75:747-749.

44. McGwin G, Sims RV, Pulley L, Roseman JM. Relations among chronic medical conditions, medications, and automobile crashes in the elderly: a population-based case-control study. Am J Epidemiol. 2000;152:424-431.

45. Meneghini RM, Smits SA. Early discharge and recovery with three minimally invasive total hip arthroplasty approaches: a preliminary study. Clin Orthop Relat Res. 2009;467:1431-1437.

46. Muh SJ, Shishani Y, Streit J, Lucas CA, Sahgal V, Kraay M, Gobezie R. The impact of joint replacement on driver function and safety. Open J Orthop. 2012;02:121-125.

47. Nguyen T, Hau R, Bartlett J. Driving reaction time before and after anterior cruciate ligament reconstruction. Knee Surg Sports Traumatol Arthrosc. 2000;8:226-230.

48. Orr J, Dowd T, Rush JK, Hsu J, Ficke J, Kirk K. The effect of immobilization devices and left-foot adapter on brake-response time. J Bone Joint Surg Am. 2010;92:2871-2877.

49. Pagnano MW, Trousdale RT, Meneghini RM, Hanssen AD. Patients preferred a mini-posterior THA to a contralateral twoincision THA. Clin Orthop Relat Res. 2006;453:156-159.
50. Pierson JL, Earles DR, Wood K. Brake response time after total knee arthroplasty: when is it safe for patients to drive? $J$ Arthroplasty. 2003;18:840-843.

51. Redelmeier DA, Tibshirani RJ. Association between cellulartelephone calls and motor vehicle collisions. $N$ Engl J Med. 1997;336:453-458.

52. Rod Fleury T, Favrat B, Belaieff W, Hoffmeyer P. Resuming motor vehicle driving following orthopaedic surgery or limb trauma. Swiss Med Wkly. 2012;142:w13716.

53. Ruel AV, Lee YY, Boles J, Boettner F, Su E, Westrich GH. A novel assessment of braking reaction time following THA using a new fully interactive driving simulator. HSS $J$. 2015;11:143-147.

54. Scott TP, Pannel W, Savin D, Ngo SS, Ellerman J, Toy K, Daubs $\mathrm{MD}, \mathrm{Lu} \mathrm{D}$, Wang JC. When is it safe to return to driving after spinal surgery? Global Spine J. 2015;5:274-281.

55. Shahid MK, Punwar S, Boulind C, Bannister G. Aircast walking boot and below-knee walking cast for avulsion fractures of the base of the fifth metatarsal: a comparative cohort study. Foot Ankle Int. 2013;34:75-79.

56. Slim K, Nini E, Forestier D, Kwiatkowski F, Panis Y, Chipponi J. Methodological index for non-randomized studies (minors): development and validation of a new instrument. ANZ J Surg. 2003;73:712-716

57. Spalding TJ, Kiss J, Kyberd P, Turner-Smith A, Simpson AH. Driver reaction times after total knee replacement. J Bone Joint Surg Br. 1994;76:754-756.

58. Thaler M, Lechner R, Foedinger B, Haid C, Kavakebi P, Galiano $\mathrm{K}$, Obwegeser A. Driving reaction time before and after surgery for lumbar disc herniation in patients with radiculopathy. Eur Spine J. 2012;21:2259-2264.

59. Thaler M, Lechner R, Foedinger B, Haid C, Kavakebi P, Galiano $\mathrm{K}$, Obwegeser A. Driving reaction time before and after surgery for disc herniation in patients with preoperative paresis. Spine J. 2015;15:918-922.

60. Tremblay MA, Corriveau H, Boissy P, Smeesters C, Hamel M, Murray JC, Cabana F. Effects of orthopaedic immobilization of the right lower limb on driving performance: an experimental study during simulated driving by healthy volunteers. $J$ Bone Joint Surg Am. 2009;91:2860-2866.

61. US Department of Health and Human Services, FDA. Risk evaluation and mitigation strategy (REMS) for extended-release and long-acting opioids. Available at: http://www.fda.gov/Drugs/ DrugSafety/InformationbyDrugClass/ucm163647.htm58. Accessed June 23, 2016

62. Wang CC, Kosinksi CJ, Schwartzberg JG, Shanklin AV. Physician's Guide to Assessing and Counseling Older Drivers. Washington, DC: National Highway Traffic Safety Administration; 2003. Available at: http://www.nhtsa.gov/people/injury/ olddrive/OlderDriversBook/pages/Acknldgment.html. Accessed July 18, 2016.

63. Waton A, Kakwani R, Cooke NJ, Litchfield D, Kok D, Middleton $\mathrm{H}$, Irwin L. Immobilisation of the knee and ankle and its impact on drivers' braking times: a driving simulator study. J Bone Joint Surg Br. 2011;93:928-931.

64. Yousri T, Jackson M. Ankle fractures: when can I drive doctor? A simulation study. Injury. 2015;46:399-404.

65. Zhu S, Layde PM, Guse CE, Laud PW, Pintar F, Nirula R, Hargarten S. Obesity and risk for death due to motor vehicle crashes. Am J Public Health. 2006;96:734-739. 